\title{
SERAT SULUK PAWESTRI SAMARIYAH: SEBUAH PENCARIAN TIRTAMARTA DALAM NUANSA KEJAWEN-KRISTIANI
}

\author{
oleh Dhanu Priyo Prabowo \\ Balai Bahasa Yogyakarta
}

\begin{abstract}
Manuscripts of Javanese literary texts with a Christian nuance are difficult to obtain. Compared with the development of the Hindu, Buddhism, and Moslem traditions in Javanese literary culture, that of the Christian tradition is still relatively new. Only a few Javanese literary texts with a Christian nuance are assumed to be currently in existence.

The writer has in hand a manuscript containing a Javanese literary text titled Serat Suluk Pawestri Samariyah. Written in the style of tembang macapat, it is to be sung aloud and, according to the year to be guessed from the four-worded Javanese phrase called a sengkalan there, it was written in 1853 in the Javanese calendar or in 1921 A.D. and got into print as a book published in 1925 by A. C. Nix \& Co., Bandung, telling about "toya gesang utawi tirtamarta sarta bab sajatining panembah", or about the life-giving water or tirtamarta and about the essence of prayers.

According to a research on the literature, Serat Suluk Pawestri Samariyah has never been scientifically studied. So this article attempts to show something new to discover in the Javanese literary tradition by disclosing an acculturation to a Christian nuance in the manuscript in the essence of its content. The word suluk itself, according to the Javanese literary tradition, is at times used to call writings containing a mystical mixture of Islamic teachings called Tasawuf and Javanese teachings called Kejawen. It is opined, however, that in the title of the manuscript it is intended to refer to the Christian nuance in the Javanese context of the text.
\end{abstract}

Keywords: Javanese literary tradition, Christian nuance

\section{A. PENDAhuluan}

Tradisi penulisan naskah Jawa yang berisi teks bernuansa Kristiani di lingkungan kesastraan Jawa masih baru jika dibandingkan dengan penulisan naskah Jawa dari lingkungan Hindu, Budha, dan Islam. Kemunculan naskahnaskah Jawa bernuansa Kristiani erat kaitannya dengan maraknya pemberitaan Injil di tanah Jawa. Menurut Jong (1976:107), kegiatan penyebaran agama Kristen terjadi di luar Jawa berlangsung sejak orang-orang Portugis, tetapi penyebaran ke lingkungan masyarakat Jawa baru berlangsung pada abad ke-19 Masehi. Dalam Sejarah Singkat Sinode Gereja Kristen Jawa (2002) diterangkan bahwa tumbuhnya gereja-gereja di tanah Jawa, khususnya di Jawa Tengah, tidak dapat dilepaskan dari peranan para pekabar Injil yang datang dari Belanda. Zaman VOC (Verenigde Oost Indische Compagnie), selama dua abad (abad XVII dan XVIII). Selama waktu tersebut tercatat adanya pengiriman tenaga pendeta secara besarbesaran. Sekitar 254 pendeta dan 800 penghibur orang sakit dengan status "pegawai VOC" 
dikirim ke Nusantara untuk melayani kepentingan "pemeliharaan rohani atas orangorang Belanda". Peristiwa ini setidaknya memberikan dampak positif terhadap munculnya gejala kekristenan di Nusantara dan khususnya di pulau Jawa. Pada masa pemerintahan kolonial Inggris di Indonesia (1811-1816), masuklah pekabar-pekabar Injil dari NZG (Nederlandsche Zendeling Genootschap) dalam rangka kerjasama dengan London Missionary Society.

Setelah Inggris tidak lagi berkuasa, Nusantara kembali berada di bawah kekuasaan Belanda. Sementara VOC dibubarkan, kekuasaan Belanda muncul dalam bentuk pemerintahan kolonial (18161942). Zaman ini merupakan masa pekabaran Injil yang banyak membawa hasil di Jawa. Dalam kurun waktu tersebut muncul gejala pekabaran Injil yang dilakukan oleh kaum awam atas inisiatif pribadi. Pekabaran Injil atas inisiatif pribadi itu menghasilkan "buah", yaitu lahirnya generasi pertama orang-orang Kristen di Jawa. Setelah itu, timbullah kelompok-kelompok Kristen di daerah Purworejo, Tegal, dan Banyumas. Mereka dibaptiskan di gereja Protestan Belanda. Baptisan pertama bagi orang-orang Jawa terjadi di Semarang (tahun 1858), di Purworejo (tahun 1860). Kelompok-kelompok tersebut merupakan cikal-bakal gereja-gereja Kristen Jawa. Dari kelompok-kelompok tersebut tersebarlah kekristenan ke Yogyakarta, Surakarta, dan ke seluruh Jawa Tengah. Latar belakang teologis para pekabar Injil awam ini tidak begitu jelas. Namun, agaknya, mereka dipengaruhi oleh gerakan Peitisme di Eropa.

Pada tahun 1816-1891 tercatat adanya pekabaran Injil yang dikerjakan oleh NGZV (Nederlandsche Gereformeerde Zendings Vereniging) di Jawa Tengah. Perkumpulan ini berasal dari lingkungan Nenerlandsche Hervormde (NHK). Dalam perkembangannya kemudian muncul pemahaman baru tentang pekabaran Injil yang langsung menjadi tanggung jawab Gereja. Sejak tahun 1892 pekabaran Injil di Jawa Tengah dilakukan oleh Gereja-Gereja Gereformeerde di Nederland (Gereformeerde Kerken in Nederland $=G K N)$.
Pekabaran Injil dilakukan baik, secara langsung maupun secara tidak langsung, melalui pelayanan di bidang pendidikan (dengan mendirikan sekolah-sekolah Zending) dan kesehatan (dengan mendirikan rumah-rumah sakit Zending). Setiap gereja GKN, baik secara sendiri-sendiri maupun gabungan beberapa gereja, menjadi "Gereja Pengutus" para pekabar Injil. Jika sebelumnya sebutan "zendeling" dipergunakan dalam pekabaran Injil, kemudian sebutan itu dihapuskan, diganti dengan sebutan "pendeta misioner". Pekabaran Injil yang dilakukan oleh Zending GKN ini menghasilkan "buah", yaitu jemaat-jemaat Kristen di berbagai tempat di Jawa Tengah. Jemaat-jemaat yang masih muda ini didorong untuk segera mandiri. Pejabat-pejabat gereja, yaitu tua-tua dan diaken, segera diangkat dari antara anggota jemaat sebagai tanda kedewasaan sebuah gereja.

Oleh karena pada abad XIX baru dalam taraf perintisan, kekristenan di tanah Jawa belumlah mengakar seperti Hindu, Budha, dan Islam. Dengan demikian, tidaklah mengherankan kalau kebanyakan kesusasteraan Jawa belum terpengaruh oleh agama Kristen (Jong, 1976:108; Sastroatmodjo, 2002:2). Keadaan itu terjadi barangkali karena sastra Jawa, oleh pekabar-pekabar Injil, dipandang sebagai sesuatu yang "merintangi" jalan bagi pekabaran Injil. Karya sastra Jawa dinilai sebagai karikatur yang bertujuan sebagai progranda kekristenan yang tidak selalu konstruksi. Di samping itu, karya sastra Jawa yang bernuansa Kristen dilihat lebih sebagai sesuatu yang destruktif di tengah-tengah orang Jawa (Partonadi, 2001:5759). Akan tetapi, di tengah kurangnya apresiasi terhadap karya sastra Jawa pada waktu itu, ternyata Serat Paramayoga dinilai lain. Van Akkeren (dalam Partonadi, 2001:57) menilai bahwa karya itu merupakan sebuah gambaran pada tingkat toleransi yang menakjubkan dan suatu bentuk kesiapan mengintegrasikan kekristenan ke dalam masyarakat Jawa. Bieger (dalam Partonadi, 2001:59) menginformasikan bahwa Het Bezoek der Wijnen uit Het oosten aan het Kindeke Jezuz "Kunjungan Orang Bijaksana dari Timur 
Kepada Kanak-Kanak Yesus" dan Strijd van Jagad Nata Met Kanjeng Nabi Ngisa "Pergumulan Antara Raja Agung Dunia dengan Yang Mulia, Nabi Ngisa" tergambar suatu apresiasi yang proporsional terhadap kekristenan. Walaupun cerita ini mengkarikaturkan Kristen dan pribadi Yesus, di dalamnya tidak terdapat petunjuk yang merendahkan Yesus. Yesus ditampilkan sebagai figur yang terhormat, seorang nabi dengan kelahiran, masa kanak-kanak, dan kehidupan yang unik. Ia dikenal sebagai Nabi Ngisa Rohullah (Yesus, Roh Allah). Memang, citra Yesus dan arti teologisnya sedikit banyak berbeda dengan yang tergambar dalam Alkitab.

Di tengah-tengah sangat minimnya naskah-naskah yang berisi teks sastra Jawa bernuansa Kristiani itu, muncul sebuah naskah berjudul Serat Suluk Pawestri Samariyah, karya Sisyaucong, ditulis pada tahun 1921 Masehi. Naskah ini kemudian diterbitkan dalam bentuk buku pada tahun 1925 oleh penerbit A.C. Nix Bandung. Serat Suluk Pawestri Samariyah bersumber dari Injil Yokanan (Yohanes), pasal 4, ayat 142, dengan perikop Gusti Yesus Wawan Sabda Karo Wong Wadon Samaria "Percakapan Yesus dengan Perempuan Samaria". Di dalam naskah tersebut, Yesus disebut dengan nama Nabi Ngisa, ditulis dalam bentuk tembang macapat melalui pupuh Dhandhanggula, Sinom, Gambuh, Mijil, dan Kinanthi.

\section{B. KAJIAN PENCARIAN TIRTAMARTA DALAM SERAT SULUK PAWESTRI SAMARIYAH}

Sebagai karya sastra berbentuk tembang, Serat Suluk Pawestri Samariyah ditulis berdasarkan konvensi macapat. Dilihat dari konvensinya, karya tersebut telah memenuhi syarat sebagai karya sastra yang estetis. Keestetisan Serat Suluk Pawestri Samariyah terlihat dari dipergunakannya (1) sandi asma, (2) waktu/kala penulisan naskah, (3) guru lagu, guru wilangan, gatra, dan (4) bahasa yang selaras dengan suasana yang dibangun.

Kehadiran Serat Suluk Pawestri
Samariyah dalam tradisi pernaskahan Jawa merupakan sesuatu yang baru. Salah satu persoalan yang menarik dari kehadiran karya tersebut adalah dengan dipergunakannya istilah suluk. Istilah suluk adalah istilah yang biasa dipergunakan dalam tradisi pernaskahan (kesastraan) Jawa yang isinya menguraikan tentang ajaran tasawuf (mistik Islam) yang bercampur dengan Kejawen. Menurut Machasin (2003) tasawuf merupakan suatu cara dan upaya untuk mendekatkan diri kepada Allah dengan jalan mengolah keadaan batin manusia. Suluk berasal dari kata Arab salaka 'jalan'. Dalam tarekat, suluk berarti perjalanan untuk membawa seseorang agar dapat sedekatdekatnya dengan Tuhan. Adapun dalam khazanah sastra Jawa, suluk berarti ajaran filsafat untuk mencari hubungan dan persatuan antara manusia dan Tuhan (Darusprapta dkk, 1990:1). Di samping itu, suluk juga terdapat dalam khazanah dunia pewayangan Jawa. Suluk dalam pewayangan Jawa merupakan vokal dalang wayang yang dilagukan dengan cengkok dan pathet tertentu yang fungsinya untuk mendukung atau menciptakan suasana sesuai dengan adegan yang ditampilkan.

Akan tetapi, di dalam Serat Suluk Pawestri Samariyah, pemakaian kata suluk tampak agak berbeda dengan pengertian suluk yang berarti "ajaran untuk mencari hubungan dan persatuan antara manusia dengan Tuhan". Suluk di sini cenderung dimaksudkan sebagai sebuah ajaran tentang keselamatan manusia dan Nabi Isa. Ajaran itu menekankan tentang jalan manusia dalam mencapai hidup yang sempurna setelah memperoleh "air hidup" (tirtamarta). Untuk mencapai kesempurnaan, di dalam ajaran itu digambarkan melalui penyembahan yang benar kepada Allah. Gambaran tentang air hidup di dalam Serat Suluk Pawestri Samariyah terungkap dalam pupuh sinom, bait 2034 sebagai berikut.

20. Yeku mung karya lantaral unggyannya yun paring wijil mimijangken kasampurnan/ sinamuning sabda lungit/mrih tumama ngenani/wenganing rasa tumlawung/ywa kaget kang 
kataman/lon manabda Jeng Nabi Ngisa/ngarah-arah noraga anamet prana/l

21. Lah babo nini rungoknalywa kagyat Ingsun jarwani/menawa sira weruha/nugrahaning Hyang Widdhi/lan weruh sireki/sapa ta kang mundhut ngunjuk/ing mau masthi sira/nuli dadi kosok bali/ mangenjali gantya nyuwun mring dheweknyal/

22. Banjur sira pinaringan/tirtamarta kang sajati/mangkana wardining basa/wiyose sabda Jeng Nabi/weh sasmita kang dhingin/nugraha saking Hyang Ngagung/tegesnya kaslametan/ pangapunten lan urip.tripakara kaacut aran nugraha/l

23. Ping kalih sasmitanya/Jeng Nabi maring pawestri/wau sinten mundhut toya/punika prasemoneki/tumrap angga Jeng Nabil nggennya mayu maweh rahayu/yuwana mring prajalma/kang yun wruh sandining ngurip/lan nanggapi nugrahanireng Hyang Suksma/l

24. Nging Sang Dyah dene tetela/ lambang kang kasbut nginggil/ mila gantya atatanya/mring Jeng Ngisa matur aris/dhuh Tuwan kadi pundi/nggyan Paduka ngambil ranu/jro sumur yen tan nyambat। Paduka tan mbekta prantil sayektine angel lamun linampahan//

25. Nggen sinten ingkang kadugal nedahken kang toya urip/kajawi sumur punika/yen wonten langkung mustail/punapa langkung inggil/Tuwan katimbang lan Yakub/luluhur kang wus kontap/Nabi Yakub duk rumiyin/pan wus karya angunjuk toya punika/l

26. Sasomahira sadaya/lembu lan mundane sami/warta wus ngombe toya/tanpa kari sawiji/mekaten Sang Pawestri/sayekti dereng sumurup/maring jatining Ngisa/lan Yakub pan langkung inggil/ kuciwane Sang Retna dereng trawacal/

27. Mung Yakub sinembah tamal ngalela punjul pribadi/makaten dadya jamaknya/watak wantuning sujanmi/cacade den sawabil alaning lyan kang cinatur/ angendhak gunaning lyan/ ngunggulken ngelmi pribadi/wus tan lepat inganggep lir toya gesang//

28. Kang gesang Ngisa wanira/rahayu praptaning ngakir/nanging pilih kang uninga/mring wadining toya urip/dahat denira rumpil/tan melok datan dumunung/sanes kang mundhut tara/kiwa tengen ngandhap nginggil/lawan dede kang wonten sajroning jaja/l

29. Kang dumunung nginggil tenggak/ lan retna kapala sami/punika sanes sadaya/upayanen den taliti/ywa klentu kawruh lair/tirta yoga iku dudu/tegese tirta yogal pan wonten kawan prakawis/kang kapisan toya kang saking pratala/l

30. Toya sing langit kalihnya/cucukul lan kang kaping tri/lan saking kang sipat nyawa/yeku taksih ewah gingsir/mung mikolehken daging/de lir goreh paminipun/tan bangkit bengkas karya/ wusanane 
balenjani/sajatine pituduh datan mangkanall

31. Wiyose kanang wawarah/widane bab toya urip/ingka ng wasta maolayat/nyatane sanget sinandhi/keh kadhung ngulati/ kajawi srana pituduh/antuk wahyuning Allah/gya dumilah anyelakil lalarahe kang tebih maksih kalingan//

32. Kataweng tigang ebab/jagad dosa miwah iblis/warna tigang prakaral upamine lir woh tiris/tabon bathok wah malih/kal a pa dadagingipun/tabon badan pamiya/wadhag kita alum aking/asli siti yun wangsul dhateng pratala/l

33. Bathok lir dosa pamiyaldadya lampitaning ngati/tyas nepsu yekti wus isak/kataman sikuning Widdhi/kalairing iblis/isbating nyawa puniku/jujul nyebal jejernya/tan ngimanken mring Hyang Lewih/luwiyane Nabi Adam duking nguni//

34. Kalimput iblis kang godha/ satemah dhawah bilahi/laila prapteng samangkin/warana tigang prakawis/panggeng tansah ngalingi/nyasabi kang toya idhup/ lir sepet bathok klapa/ngalingi toyaning tiris/mila Sang Dyah Samariyah langkung kasmaran//

(SSPS, sinom, 2034)

Adapun terjemahannya adalah sebagai berikut.

20. Semua itu hanya sebagai lantaran/ dalam rangka ingin menyampaikan maksud/ajaran kesempurnaan/ firman yang berharga/agar sampai tujuan/terbuka lebar rasa/agar tak terkejut yang mendengar/pelan bersabda Nabi Isa/dipilih kata yang menyejukkan hati//

21. Dengarkanlah hai perempuan/ jangan terkejut aku beritahu/agar engkau tahu/anugerah Tuhan/dan supaya engkau tahu/siapa yang meminta minum/nanti engkau pasti akan/berbalik/memohon kepadaNya//

22. Lalu engkau akan menerima/air kehidupan yang sejati/demikian inti ajaran/sabda Nabi Ngisa/ memberi pertanda yang pertama anugerah dari Tuhan yang Agung/yang berarti keselamatan/ pengampunan dan hidup/ ketiganya disatukan sebagai anugerah//

23. Pertanda yang kedua/dari Kanjeng Nabi kepada si perempuan/ yang sedang mengambil air/itu adalah penggambaran/atas diri Kanjeng Nabi/dalam rangka memberi keselamatan/kepada setiap manusia/yang ingin mengetahui rahasia kehidupan/dan berterima kasih atas anugerah Tuhan//

24. Sang Perempuan ingin mengetahui/atas perlambang tersebut/lalu bertanya/pada Kanjeng Isa dengan pelan/duh, Tuan, bagaimana caranya/Paduka mengambil air/ di dalam sumur jika tak minta tolong/Paduka tidak membawa peralatan/sungguh sulit terlaksana//

25. Siapa yang mampu/menunjukkan di mana air hidup/kecuali hanya sumur ini/jika ada yang melebihi itu mustahil/apakah lebih tinggi/ Tuan dibandingkan dengan Yakub/leluhur yang sudah diakui/ 
Nabi Yakub dahulu/juga meminum dari air sumur ini//

26. Dengan seluruh keluarganya/ demikian juga lembu dan dombanya/ semua telah meminum air ini/tiada yang terkecuali/ demikian Sang Perempuan/ sebenarnya belum mengetahui/ atas sejatinya Isa/karena menganggap Yakub lebih tinggi/ sayang ia belum mengetahui//

27. Terbukti hanya Yakub yang diketahui/melebihi yang lain/ demikian sudah biasa terjadi/ watak manusia/ kekurangannya sendiri disembunyikan/keburukan orang lain dibicarakan/ meremehkan kemampuan orang lain/ mengunggulkan kemampruan pribadi/sudah merasa benar menganggap air kehidupan//

28. Yang hidup Isa/selamat hingga akhir zaman/tetapi perlu diketahui/ atas rahasia air kehidupan/sungguh rumit/tak begitu saja dapat diketahui/bukan air yang diambil/ dari kanan kiri bawah atas/dan bukan yang ada di dalam dada//

29. Yang berada di atas leher/dan ratna di kepala semuanya bukan itu/ carilah dengan teliti/jangan keliru dengan ilmu dunia/air doa juga bukan/artinya air doa/ada empat hal/air yang berasal dari tanah//

30. Kedua air dari langit/ketiga air dari tetumbuhan/dan keempat air yang bersifat nyawa/itu masih berubahubah/hanya menyenangkan daging/jika berubah misalnya takkan mampu mengatasi masalah/ akhirnya mengingkari/sejatinya petunjuk (ajaran) tidak demikian//
31. Lahirnya sebuah ajaran/tentang harumnya air kehidupan/yang bernama mati hidup/sebenarnya sangat samar/banyak yang mengamati/kecuali dengan cara petunjuk/ mendapat wahyu dari Allah/segera terang mendekati/letaknya jauh masih terhalang//

32. Terhalang oleh tiga hal/dunia dosa dan iblis/tiga hal tersebut/seumpama buah kelapa/sabut batok dan lagi/daging kelapa/sabut semisal badan/tubuh kita alum dan kering/berasal dari tanah kembali pada tanah//

33. Batok diumpamakan dosa/jadi perlambang hati/hati bernafsu bukti telah rusak/terkena hukuman Tuhan/maksudnya iblis/ibarat nyawa/me-nyeleweng adanya/tak percaya pada Tuhan Maha Lebih/yang melebihi Nabi Adam dahulu//

34. Hati tergoda iblis/akhirnya membawa maut/hingga nanti akhirnya/ pintu berupa tiga hal/selalu dijumpai dan menghalangi/ mengalahkan air kehidupan/ bagaikan sabut kelapa/ menghalangi air kelapa/maka Perempuan Samariyah semakin tertarik//

Dalam teks tersebut, Perempuan Samariyah digambarkan sedang belajar tentang makna "air kehidupan" pada Nabi Ngisa di Sumur Yakub. Air kehidupan bukan "air yang bersifat fisik". Air yang berasal dari Sumur Yakub hanya dapat memberikan kesegaran bagi tubuh manusia dan tidak dapat memberikan pencerahan bagi rohani manusia. Oleh karena itu, manusia memerlukan "air kehidupan" agar hidupnya memperoleh pencerahan. Demikian pula bagi Perempuan Samariyah jika ingin 
memperoleh air kehidupan harus memahami cara memperolehnya, yaitu dengan menempuh hidup yang benar sesuai dengan perintah Tuhan. Dengan hidup selaras dengan perintah Tuhan, ia akan memperoleh pengampunan dan keselamatan. Kedua hal itu merupakan anugerah Tuhan. Anugerah Tuhan tidak dapat diperoleh dengan peralatan fisik (timba), tetapi harus diperoleh dengan melakukan perjalanan rohani (menelusuri jalan Tuhan). Jalan Tuhan akan terbuka apabila manusia (baca Perempuan Samariyah) meninggalkan keburukan yang ditimbulkan oleh dunia, karena keburukan seperti itu menjadi penghalang. Penghalang itu berupa dunia, dosa, dan iblis yang diibaratkan dengan sabut, batok, dan daging kelapa. Jika ketiga hal itu dapat dilampaui, maka manusia akan memperoleh air kehidupan (kesempurnaan hidup).

Konsep tentang air hidup sebagaimana yang dijumpai di dalam Serat Suluk Pawestri Samariyah juga ditemukan dalam cerita Dewa Ruci. Di dalam cerita tersebut, Bima diperintahkan oleh Dhurna untuk mencari air hidup. Dalam Dewa Ruci, air hidup dinamakan Tritaperwita atau sering juga disebut Tirtaamerta. Diterangkan Sastroamidjojo (1967:10) air hidup itu bermakna "air untuk menyucikan badan dan suksma". Setelah jiwa dan raga bersih atau suci (karena air itu), orang lalu dapat menyadari sajatining gesang "hakikat hidup atau hidup yang wajar, yang sejati". Dalam keadaan seperti itu, orang yang memperoleh air kehidupan akan dapat mengetahui sangkan paraning dumadi "asal", tujuan, dan arah hidup manusia pada umumnya". Dibayangkan oleh Dhurna, bahwa orang yang memiliki air hidup akan mencapai tingkat hidup yang serba sempurna, hidup yang suci. Oleh karena itu, orang yang mencapai air tersebut akan memiliki "ilmu kebebasan jiwa". Dalam hubungan ini, Dhurna dimaknakan sebagai lambang angan-angan atau budi yang menguasai dan menggiatkan perasaan AKU, yang diperlambangkan dengan tokoh Bima. Untuk memperoleh air hidup tersebut tidak mudah karena Bima harus masuk ke dalam "gua gaib" yang berbentuk sumur gumuling (kudus, dahsyat). Tempat itu terletak di Gunung Candramuka atau Reksamuka. Menurut Mulyono (1982:33) perjalanan Bima untuk mencari air hidup sebenarnya merupakan suatu perwujudan bersatunya dirinya dengan Hyang Otipati (Mahasuci) dan disebut "suluk" atau mistikisme. Dalam mistik Jawa, kata jumbuhing kawula Gusti "berarti bersatunya hamba dan Tuhan" melukiskan tujuan tertinggi dalam hidup manusia, yaitu tercapainya "kesatuan" yang sesungguhnya (manunggal) dengan Tuhan (Moertono, 1985:18).

Tema seperti tersebut (suluk atau mistik), intertekstual dengan peristiwa yang ditemukan dalam diri Pawestri Samariyah (Perempuan Samaria). Untuk mendapat hidup yang sempurna (hidup baru), Perempuan Samaria harus membuang hidup yang lama, hidup yang masih dipenuhi dengan cadar (aling-aling). Cadar itu adalah "dunia", "dosa", dan "iblis". Ketiganya diibaratkan buah kelapa. Dunia ibarat sabut, dosa ibarat batok kelapa, dan iblis daging kelapa. Air hidup (tirtamarta) itu diperoleh bukan karena pencarian pribadi saja, melainkan karena karya Allah yang terwujud dalam diri Perempuan Samaria: /kajawi srana pituduh/antuk wahyuning Allah/gya dumilah anyelaki/lalarahe kang tebih maksih kalingan// Kenyataan ini tergambar dalam pupuh dhandhanggula baris 15 dan 16 sebagai berikut.

15. Tan mangkana sababing wigati/pambukanya kang kinantha ring Hyang/mangkana pan wus pasthine/dhawahireng kang wahyu/nugrahane punang pawestri/manggih lan Nabi Ngisa/Nabi diya anung/utusanira Hyang Suksma/maweh marta mastawa sameng dumadi/mamayu yuningjagad//

16. Nabi Ngisa tan samar pangeksi/mring pawestri kang tigas kawuryan/kang dadyanira ing tembe/sinawang calon punjul/bisa tampi wasiteng gaib/wus pinasthi dening 
Hyang/rahayu tinemu/ing dunya prapteng ngakerat/Kanjeng Nabi arsa ngruwat ing pawestril tarunaning tyasira/l

(SSPS, Dhandhanggula, 1516)

Terjemahannya adalah sebagai berikut.

15. Demikianlah inti persoalab/ajaran pembukaan yang digambarkan Tuhan/demikianlah sudah menjadi kepastianNya/turunnya wahyu/ anugerah untuk perempuan/yang dari Nabi Ngisa/Nabi utusan/Tuhan memberi kabar kesukaan kepada setiap manusia/ membuat damai dunia//

16. Nabi Ngisa tak ragu melihat/ perempuan yang masih suci hatinya/yang besuk akan menjadi/ terlihat unggul/menerima wahyu/ sudah dipastikan Tuhan/ memperoleh keselamatan/di dunia hingga di akherat/Kanjeng Nabi hendak meruwat perempuan itu/ demikianlah kehendakNya//

Secara substantif, antara Dewa Ruci dan Serat Suluk Pawestri Samariyah, memiliki nuansa konsep tentang cara memperoleh air hidup (kesempurnaan). Yang disebut pada yang pertama (Dewa Ruci) karena upaya pribadi Bima; yang kedua (Perempuan Samaria), di samping karena pencarian diri pribadi, juga karena anugerah/wahyu Tuhan. Tanpa anugerah (dipanggil) Tuhan tidak mungkin akan memperoleh kesempurnaan hidup. Namun, antara keduanya memiliki kesamaan tema, yaitu memperoleh kesempurnaan hidup melalui perlambangan air hidup (tirta amerta atau tirtamarta). Melalui tema atau topik tirtaamerta atau tirtamarta atau toya marta, Serat Suluk Pawestri Samariyah mampu mengangkat suasana yang selaras dengan budaya Jawa, khsususnya Kejawen. Hal ini semakin tampak dalam pupuh gambuh bait 51, 56, dan 57 sebagai berikut.
51. Wondene ugeripun/anggen kita ayun mangsah sujud/marang Allah pan wonten prakawis/wanuh karuh weruh kukuh/tegesira kang cumeplong//

56. Wauta Sang Retnayu/samya padhang namping ngelmu/ kasampurnan sangkan paraning dumadi/rarasing rasa rasa kacakup/kapusthi sajroning batos//

67. Lir gesang jroning lampus/pan mangkana ing pangraosipun/Sang Wanodya dening tuk nugraha jati/wus lama gyanira luruh/ utusanira Hyang Manon//

(SSPS, Gambuh, 51, 56, 57)

Adapun terjemahannya adalah sebagai berikut.

51. Adapun dasarnya/dalam kita berbakti/kepada Allah ada empat hal/wanuh karuh weruh $\boldsymbol{k u} \boldsymbol{k} \boldsymbol{u h} /$ maksudnya adalah//

56. Demikianlah Perempuan dari Samaria itu/terang dalam menerima ilmu/kesempurnaan awal akhir alam semesta/keinginan hati terpenuhi/tertanam di dalam batin//

57. Bagaikan hidup dalam kematian/ demikian perasaan hatinya/ Perempuan Samaria telah memperoleh anugerah/telah lama ia mencari/utusan Tuhan

Perempuan Samaria itu telah menerima pencerahan karena ia sudah wanih (mengetahui bahwa Allah yang patut disembah dengan hati suci), karuh (semua keinginan pribadinya hanya tertuju kepada Allah), weruh (mengetahui semua permintaannya hanya didasarkan kepada Allah), dan kukuh (mempercayai bahwa Nabi Isa adalah Juru 
Selamat). Persoalan tersebut mirip dengan Kejawen. Menurut Ciptoprawiro (1986:22) pencarian manusia akan berakhir dengan wikan, weruh atau mengerti sangkan paran. Dalam filsafat Jawa sepanjang masa, orang Jawa berkesimpulan bahwa Tuhan merupakan Sangkan Paraning Dumadi: (1) awal berasal dari Tuhan, dan (2) akhir berarti kembali kepada Tuhan, Usaha manusia untuk kembali pada asalnya atau kembali kepada Tuhan dilakukan dengan jalan jasmani maupun rohani, atau jalan lahir dan jalan batin. Jalan batin ini biasanya disebut mistik atau mistikisme.

Di dalam kutipan tadi (bait ke 57) diungkapkan bahwa Perempaun Samaria Lir gesang jroning lampus "bagaikan hidup dalam kematian" setelah menemukan Nabi Ngisa yang telah lama dicarinya. Ia juga merasakan memperoleh anugerah setelah dapat memahami makna wanuh karuh weruh kukuh. Konsep "bagaikan hidup dalam kematian" seperti yang ditemukan oleh Perempuan Samaria ini, di dalam Kebatinan Jawa, intertekstual dengan dialog antara Seh Malaya dan Sunan Bonang (dalam Poerbatjaraka, 1985:44). Di dalam dialog itu Seh Malaya bertanya kepada Sunan Bonang: "Apakah ada keadaan tanpa nama atau nama tanpa keadaan? Katakanlah kepadaku sebagai pegangan akhir." Jawaban Sunan Bonang: "Jika kau menginginkan pegangan akhir, matikanlah badanmu, berlatihlah untuk mati selagi kau masih hidup. Pergilah ke tempat sunyi dalam rimba, jangan bergaul dengan orang." Setelah itu, Seh Malaya masuk ke hutan untuk hidup bersama dengan rusa. Satu tahun kemudian, Sunan Bonang datang menengok Seh Malaya. Didapatinya Seh Malaya berlaku seperti kijang. Ia menjadi liar tidak mau didekati manusia. Akhirnya, Sunan Bonang berhasil menangkapnya dengan jalan melempar tiga buah bola nasi. Setelah Seh Malaya menjadi "jinak", Sunan Bonang lalu memerintahkan kepadanya bahwa ia harus menjalankan haji ke Mekah, guna mengambil air zam-zam (sebagai pengganti toyamartaair hidupdari Dewa Ruci) di dekat Ka'bah, selain itu juga untuk mendapatkan restu dari Nabi Muhammad.
Konsep seperti tersebut di atas menunjukkan adanya suatu "benang merah" yang menghubungkan antara tradisi Kejawen dan Kristiani di dalam teks Serat Suluk Pawestri Samariyah. Walaupun antara kedua tradisi tersebut terdapat nuansa, nuansa tersebut justru sangat membantu pemahaman atas dua perbedaan yang ada antara kedua tradisi tersebut (Kristiani dan Kejawen). Pada satu sisi, kehadiran Serat Suluk Pawestri Samariyah sebagai karya sastra Jawa dapat selaras dengan alam pikiran Kejawen; pada sisi yang lain, konsep tentang jalan memperoleh air hidup (kesempurnaan) antara Kejawen dan Kristiani dapat dipergunakan sebagai wacana dialogis tentang kemanusiaan, toleransi, dan kebersamaan di tengah pergaulan budaya manusia.

Penyebutan nama Nabi Ngisa di dalam Serat Suluk Pawestri Samariyah merupakan suatu strategi budaya yang akulturatif di tengah kebudayaan Jawa. Pemakaian nama Nabi Ngisa di dalam Serat Suluk Pawestri Samariyah secara teologis memang membawa nuansa dan citra yang terdapat dalam Alkitab. Walaupun citra Yesus dalam arti teologis agak berbeda dengan yang tergambar di dalam Alkitab, kehadiran Serat Suluk Pawestri Samariyah tetap merupakan suatu karya yang menarik dalam dunia kesastraan. Lewat karya tersebut, pekabaran Injil menjadi lebih alkuturatif, karena budaya Jawa tetap diperhatikan posisinya tanpa harus kehilangan inti masalah. Jika Akkeren (dalam Partonadi, 2001:57) pernah mengalami kekhawatiran ketika membaca Serat Paramayoga, kehadiran Serat Suluk Pawestri Samariyah secara tidak langsung telah menepis kekhawatiran tersebut. Karya seni (sastra) Jawa ternyata dapat menjadi suatu sarana yang dinamis dan fleksibel untuk media ekspresi religius. Hal ini telah dibuktikan Kiai Sadrach Suraprana bersama jemaatnya dengan mendayagunakan tembang-tembang Jawa dalam membangun persekutuan malam hari untuk persahabatan. 


\section{SIMPULAN}

Perintisan kekristenan di tanah Jawa baru dimulai pada abad XIX. Oleh karena kekristenan masih baru, tradisi penulisan naskah Jawa yang berisi teks bernuansa Kristiani di lingkungan kesastraan Jawa belum mengakar seperti yang terdapat dalam tradisi Hindu, Budha, dan Islam. Tidaklah mengherankan kalau kebanyakan kesusasteraan Jawa belum terpengaruh oleh agama Kristen. Pada awalnya, karya sastra Jawa yang bersuasana Kristen/Kristiani dipandang sebagai sesuatu yang "merintangi" jalan bagi pekabaran Injil dan dinilai sebagai karikatur dalam pewartaan kekristenan. Bahkan, karya sastra Jawa dipandang tidak selalu konstruktif. Citra Yesus dalam arti teologis agak berbeda dengan citra Yesus yang tergambar dalam Alkitab, tetapi kehadiran Serat Suluk Pawestri Samariyah merupakan suatu sumbangan yang menarik dalam dunia kesastraan Jawa tanpa harus kehilangan esensinya. Kemenarikan itu terletak pada nilai akulturasi antara tradisi Kristen dan Kejawen. Nuansa Kejawen-Kristiani berhasil ditampilkan di dalam Serat Suluk Pawestri Samariyah. Melalui tema atau topik tirtaamerta/toya marta/tirtamarta, karya itu mampu mengangkat suasana yang selaras dengan budaya Jawa.

\section{DAFTAR PUSTAKA}

Darusuprapta dkk. 1990. Ajaran Moral dalam Susastra Suluk. Jakatya; Pusat Pembinaan dan Pengembangan Bahasa.

Jong, De. 1976. Salah Satu Sikap Hidup Orang Jawa. Yogyakarta: Kanisius.

Machasin. 2003. "Manunggaling Kawula Gusti: Tinjauan Tasawuf Islam". Dalam Seminar Nasional Menggali Karya Puncak P.J. Zoetmulder, S.J. Universitas Sasnata Darma, Yogyakarta.

Moertono, Soemarsaid. 1985. Negara dan
Usaha Bina-Negara di Jawa Masa Lampau; Studi tentang Masa Mataram II Abd XVI sampai XIX. Jakarta: Yayasan Obor Indonesia.

Mulyono, Sri. 1982. Wayang dan Filsafat Nusantara. Jakarta: Jambatan.

Partonadi, Soetarman Soediman. 2001. Komunitas Sadrach dan Akar Kontekstualnya: Suatu Ekspresi Kekristenan Jawa Pada Abad XIX. JakartaYogyakarta: P.T. BPK Gunung MuliaTaman Pustaka Kristen.

Poerbatjaraka, R. Ng. 1985. Ajaran Rahasia Sunan Bonang. Jakarta: Departemen Pendidikan dan Kebudayaan, Proyek Penerbitan Buku Sastra Indonesia dan Daerah.

Sastroamidjo, A. Seno. 1967. Cerita Dewa Ruci dengan Arti Filsafatnya. Jakarta: Penerbit Kinta.

Sastroatmodjo, Suryanto. 2002. "'Sosok Kristus dan 'Rasa Kristiani' dalam Krida Sastra Jawa". Dalam Diskusi Kebudayaan Jawa dan Realitas Dinamuka Kehidupan Bergereja. Karangjasa, Kuartarja, Purworejo. 